\title{
Interactive comment on "Biogeochemical evidence of anaerobic methane oxidation and anaerobic ammonium oxidation in a stratified lake using stable isotopes" by Florian Einsiedl et al.
}

\section{Anonymous Referee \#2}

Received and published: 23 April 2020

The authors present a comprehensive data set (at least in terms of the number of measured parameters) on concentration profiles and corresponding stable isotope compositions of $\mathrm{CH} 4$, nitrate, nitrite, and ammonium in the water column of a stratified lake, suggesting links between anaerobic oxidation of methane (AOM), denitrification, and anammox. They attribute a nitrate methane transition zone to nitrate-dependent methane oxidation, and claim, based on model fitting approaches, that the observed methane profiles cannot be explained by microaerobic methane oxidation, and that coupling to denitrification is most likely. I do not think that the combined isotope profiles are that compelling with regards to their interpretation, and the respective enrichments in $15 \mathrm{~N}$ in the ammonium and nitrate pools at around $20 \mathrm{~m}$ depths could also be due

Printer-friendly version

Discussion paper 
to denitrification and ammonium oxidation in close vicinity. Similarly, several scenarios may be possible to explain the observed offset in D15N between nitrite and nitrate. Nevertheless, it is a nice data set, and the authors do a good job in trying to interpret the data set in an attractive way. Additional evidence comes from molecular data, confirming the presence of the microbial players that potentially perform anammox and nitrate-dependent AOM. But there are no additional conclusive evidence on coupled $\mathrm{N}$ reduction and $\mathrm{CH} 4$ oxidation, and a more quantitative assessment with regards to the importance of these microbes, as well as turnover rates is missing. Clearly, incubation experiments with different electron acceptors would help. As a consequence, it remains uncertain, which processes truly govern the observed isotope profiles and in turn it is difficult to understand how important these combined processes are in regulating methane emissions and nitrogen concentrations in the studied lake, let alone in other lakes. The authors mention the limitations of their approach, but still, I would advise a more cautious interpretation of the data. To me this looks like a quite common seasonally stratified lake with very typical seasonal biogeochemical dynamics and processes. In this regard, I am afraid that the claimed "unique biogeochemistry" is a bit of an overselling. Most importantly, as I will outline below, I felt that the modelling is not sound, and the interpretation of isotope profiles "by eye" in a system that may not be in steady state problematic.

Main points:

Abstract: In light of much more important $\mathrm{N}$-loss reactions (denitrification anammox) I think it is an exaggeration to state that nitrate-dependent methane oxidation has the potential to reduce nitrate loading. It just does not happen, we know that. I doubt that AOM-denitrification-anammox process really is an overlooked process. . it simply is less important than canonical denitrification and aerobic methane oxidation. There is no information on the site/lake. The name and location of the lake should at least be mentioned.

Printer-friendly version

Discussion paper

The introduction is good, and provides more or less up-to-date info on AOM and anam- 
mox in freshwater ecosystems. Maybe it needs to be distinguished better between studies that were conducted in the field versus those that are purely experimental. This is not completely clear for someone who did not read the papers.

L56: Why is nitrate reduction more important in lakes than nitrite reduction, just because there is more nitrate than nitrite? Nitrite is an intermediate and assuming that the most important $\mathrm{N}$ loss pathway is complete denitrification, nitrite reduction has to balance nitrate reduction, if nitrite does not accumulate.

L88: ". . .coupled the diffusion model with a degradation term to clarify the effect of dissolved oxygen on methane oxidation. The observed coupled process has the potential to constitute an important sink of dissolved nitrogen (NO3-, NO2-, NH4+) and methane $(\mathrm{CH} 4)$ in freshwater environments." What exactly is coupled? What coupled process are the authors referring to? This is not clear at this point of the article what they did in the model and how $\mathrm{O} 2$ thresholds are integrated. Even if an explanation will follow in the method section, this needs to be clarified (or moved to the more detailed sections on the model parametrization).

Model: There is not enough explanation of the model. Obviously, it is not a real reaction-diffusion model, but it also is not just a diffusion model, right? What are the reaction parameters, how are they set? I am not an expert in modelling, but it remains unclear how the modelling works, apparently, a purely diffusive part and a reaction part is combined, but the coupling of the model components is unclear. Most importantly, how well constrained is turbulent diffusion? The results (modelled concentration profiles and isotope ratios in water column) will be highly sensitive to the choice of the D, and adopting values for $D$ (by the way $D$ is used usually for molecular diffusion only) from other lakes may not be appropriate. In fact, the authors seem to have a very limited knowledge of modelling turbulent diffusion in lakes. Firstly, it seems that their choice of what they call $\mathrm{D}$ (or $\mathrm{K}$ in the literature) is at least two orders of magnitude higher than would be expected for a stratified lake. They cite Oswald et al. from which $\mathrm{D}$ was adopted. But looking into the paper by Oswald, I saw that their choice of $\mathrm{Kz}$

Printer-friendly version

Discussion paper
Interactive comment 
was $4 \times 10-3 \mathrm{~cm} 2 \mathrm{~s}-1$, which corresponds to approx. $0.035 \mathrm{~m} 2 \mathrm{~d}-1$. If the authors really used $\mathrm{D} / \mathrm{Kz}$ values between 0.1 and 2.1 , their modelled concentrations will be way off. Finally, assuming different turbulent diffusion coefficients for $\mathrm{O} 2$ and $\mathrm{CH} 4$ is nonsense. Turbulent diffusion is not solute-specific (in contrast to molecular diffusion), it is a hydrodynamic property of the flow field. As for the first-order methane oxidation rate coefficient, how can the authors just assume a value adopted from other studies? This parameter will change significantly between ecosystems, and has to be estimated based on fitting of the model to the observational data.

Nitrate/nitrite isotope measurements: The authors write: Nitrogen and oxygen isotope ratios of nitrate were calculated by measuring nitrite alone as well as the mixture of nitrite and nitrate in a sample and using an inverse mixing calculation to determine the isotopic ratios of nitrate alone. First of all, there seems to be a duplication in this sentence. I think I understand what the authors did. They measured the isotopic composition of nitrite, and then the isotopic composition of the mixture. Based on mass balance calculation, they then calculate the isotopic ratios of nitrate alone. This works for $\mathrm{d} 15 \mathrm{~N}$, but does it work for $\mathrm{d} 18 \mathrm{O}$ ? I am pretty sure that it does not. In a sample that contains nitrite and nitrate, $\mathrm{O}$ isotope fractionation during the conversion to $\mathrm{N} 2 \mathrm{O}$ is different for nitrite and nitrate. Hence the d18O of the $\mathrm{N} 2 \mathrm{O}$ cannot simply be standardized, because the O-isotope offsets will be different for nitrite and nitrate. In other words, the $\mathrm{d} 180$ of a NOx sample is probably meaningless, and so will be the calculated $\mathrm{d} 180$ nitrate values. The nitrate $\mathrm{d} 180$ should have been measured after removal of the nitrite. Could the changes in $\mathrm{Dd} 15 \mathrm{~N}$ (nitrate-nitrite) be an artifact that is simply the result of this effect and changing nitrite/nitrate concentration ratios?

L188: How was complete outgassing of $\mathrm{CH} 4$ assured before headspace analysis? Was brine/ $\mathrm{NaOH}$ added? Concentrations were calculated based on Henry's Law, but what about the $\mathrm{d} 13 \mathrm{C}$ ? Is there an isotope shift between $\mathrm{CH} 4$ in the headspace and the $\mathrm{CH} 4$ dissolved? If so, was that considered?

Printer-friendly version

Discussion paper

Results: I am a bit disappointed by the low number of data points/analyses. As a 
consequence, isotope gradients are not well resolved (and their interpretation is hence complicated), and the profiles are not replicated for several time points. Do the authors assume steady state conditions? How relevant is this for the model fitting?

Figure $3 c$ is very difficult to read? Why not showing profiles (connected symbols) for the most relevant OTUs. It is almost impossible to see the vertical structure.

Discussion: It is not clear to me what the arguments are that allow the authors to exclude oxic methane oxidation. I agree that the concentration profile suggests reaction below the redoxcline, but you do not need to model this to come to this conclusion. At the same time, do the authors assume steady state? Apparently, the lake undergoes seasonal fluctuations, so that the curvature of the concentration profiles may represent a non-steady state, and its interpretation with regards to where reaction takes place and where not is biased.

Again, maybe it is my fault, but I got the feeling that, overall, the modelling is not sound (or that it is simply not the right model, comprehensive enough to realistically simulate the different interlinked processes), and so are the conclusions drawn from the modelling. But maybe I just did not understand it. For example, in L298-303: How was the model used to test whether microaerobic respiration plays a role or not? I am sure that, depending on the half-saturation constants, the diffusivity, and the rate coefficient, a model with solely microaerobic methane oxidation could generate the methane profile observed, while keeping the $\mathrm{O} 2$ levels close to detection. But again, can steady state be assumed at all?

L319: From my understanding, the methane ÏAd'13C increase below the redoxcline does not necessarily indicate AOM. I am not saying that it is not AOM that causes the increase in ÏAd' 13C. But even if methane oxidation occurred only in a relatively thin layer further up in the water column, we would see a ÏAqd' $13 \mathrm{C}$ gradient. The authors should model not only the concentration, but also the different $\mathrm{CH} 4$ species (i.e,ïĂăïĄd' $13 \mathrm{CH} 4)$, then they would probably see it.

Printer-friendly version

Discussion paper 
Can the authors explain why a $90 \%$ decrease in ammonium is associated with a İĄd'15N shift of only 4\%。 L335-7: The authors say that above $20 \mathrm{~m}$ water depth, there is no evidence for ammonium oxidation. Why? Because the d15NH4 values do not increase? But they also do not increase much below that depth, where the authors suggest that anammox occurs. And most strikingly, the ammonium profile is essentially linear all the way up to the oxycline. To me this suggests that not much ammonium oxidation is taking place at this depth, and essentiall all NH4 is oxidized at the oxycline.

340-345: The authors cite the anammox isotope effect study by Brunner and colleagues. But they mix up equilibrium and kinetic $\mathrm{N}$ isotope effects between nitrite and nitrate. The inverse kinetic $\mathrm{N}$ isotope effect, which applies to active nitrate production from nitrite by anammox, is much lower than the $-61 \%$ mentioned.

The authors should explain better why anammox could produce a d18O vs d15N NO3 relationship of 0.5 . Is this slope consistent with nitrate production from nitrite with the incorporation of $\mathrm{O}$ atoms from water? Such slopes in $\mathrm{d} 18 \mathrm{O}$ vs d15N NO3 plots have been observed in several ground/freshwater studies. Does this imply that in all these environments anammox was the main $\mathrm{N}$-loss pathway?

What is the relative abundance of "normal" nitrate and nitrite reducers compared to NC10 and Crenothrix?

General: The paper is prepared with a certain degree of carelessness, with a lot of typos and sometimes odd wording.

Minor points: L32: geochemical L47: coupled L54: affects the reduction? The whole sentence, at least the final part, does not read well L84: Not overlapping isotope values but overlapping $C$ isotope effects! L120: mgN? Otherwise it is surprising that the detection limit is the same for the different N-components. L262: counter-gradients? 314: What is the stable isotope technique? Simple isotope measurements? L372: Metabolism L382: portion

Printer-friendly version

Discussion paper 
Interactive comment on Biogeosciences Discuss., https://doi.org/10.5194/bg-2020-18, 2020.

Interactive

comment 